\title{
Vivências de prazer e sofrimento mental em um Centro de Atenção Psicossocial
}

\author{
Pleasure and mental suffering experience at a Center of Psychosocial Care
}

\author{
» Ariane Priscila Fonseca AZEVEDO ${ }^{1}$ (Universidade Federal do Mato Grosso do Sul, Brasil) \\ » Vanessa Catherina Neumann FIGUEIREDO² (Universidade Federal de Mato Grosso do Sul, Brasil)
}

\section{Resumo}

$\mathrm{O}$ artigo relata a investigação das vivências de prazer e de sofrimento mental na equipe de profissionais de saúde que atende pessoas com transtornos mentais em um Centro de Atenção Psicossocial (CAPS), localizado no interior do Mato Grosso do Sul, em 2012. A partir da abordagem da psicodinâmica do trabalho foram analisadas as condições e a organização do trabalho prescrito e real, a mobilização criativa e a existência de sofrimento e patologias. Onze trabalhadores participaram de cinco entrevistas coletivas, que abordaram exigências técnicas, relações sociolaborais, riscos, tarefas, normas, gestão, divisão do trabalho, responsabilidades, aplicação da inteligência prática e cooperação, existência de sofrimento criativo e reconhecimento. A presença de sofrimento patogênico e danos físicos ou psicossociais foram avaliados pela Escala de Prazer-Sofrimento no Trabalho (ESPST) e pela Escala de Sintomas Relacionados ao Trabalho (ESRT), que integram o Inventário de Trabalho e Riscos de Adoecimento (ITRA). Verificou-se que as principais vivências de prazer estão relacionadas ao modo como a equipe se relaciona, ao reconhecimento por parte dos usuários e dos familiares, e à autonomia para planejar suas atividades. A falta de reconhecimento por parte da gestão, a falta de segurança nos atendimentos e a sobrecarga de trabalho foram aspectos geradores de sofrimento. Os resultados da EPST nos itens Realização profissional $(3,6)$ e Liberdade de expressão $(4,2)$ indicam que as estratégias de mediação do sofrimento se equilibram na equipe por meio da dinâmica do reconhecimento. A ESRT aponta para um risco moderado de sintomas e doenças físicas relacionadas à sobrecarga de trabalho.

Palavras-chave:

sofrimento; saúde mental; psicodinâmica.

Abstract

The article reports on the investigation of pleasure and mental suffering experiences of the team of health professionals treating persons with mental disorders, in a Center for Psychosocial Care (CAPS), located in Mato Grosso do Sul, in 2012. Using the Psychodynamic approach of work, the prescribed and real working conditions and organization, the creative mobilization and the existence of suffering and pathology were analyzed. Eleven workers participated in five group interviews, which addressed technical requirements, sociolabor relationships, risks, tasks, standards, management, division of labor, responsibilities, application of practical intelligence and cooperation, existence and recognition of creative suffering. The presence of pathogenic suffering and physical and psychosocial damage were assessed by the Scale of Pleasure-Suffering at Work (ESPST) and the Symptoms Related to Work Scale (ESRT), which are part of the Register of Work and Risk of Illness (ITRA). It was found that the major experiences of pleasure are related to how the team interacts between them, to the recognition by patients and families, and the autonomy to plan their activities. The lack of recognition by the management, the safety uncertainty of the patients care and the excessive workload generated various aspects of the suffering. The results of EPST for Professional Achievement (3.6) and Freedom of Expression (4.2) indicate that mediation strategies of suffering were balanced in the team, by the recognition dynamics. The ESRT pointed to a moderate risk of physical symptoms and illnesses related to labor overload.

Keywords:

suffering; mental health; psychodynamic.

\footnotetext{
1 Psicóloga graduada pela Universidade Federal de Mato Grosso do Sul em Março/2013. Endereço: Rua Portuguesa, 501, casa 1, Vila Maciel, Campo Grande - MS - CEP: 79070-320 - Telefone: (67) 9673-4135. E-mail: ariane-azevedo18@ hotmail.com

2 Psicóloga formada pela UNESP de Bauru, com doutorado em Saúde Coletiva, Professora Adjunta da Universidade Federal de Mato Grosso do Sul, Campus do Pantanal, no curso de graduação em Psicologia, no mestrado em Educação Social e no mestrado em Estudos Fronteiriços; líder do grupo de pesquisa Saúde Mental e Trabalho na Fronteira e coordenadora do Laboratório de Psicologia do Trabalho e Saúde Coletiva. Endereço: Universidade Federal de Mato Grosso do Sul - Laboratório de Psicologia do Trabalho e Saúde Coletiva - Avenida Rio Branco, 1270, Bairro Universitário, Corumbá- MS - CEP: 79.304-902 - Telefone: (67) 3234-6891/ Fax: (67) 3234-6810. E-mails: vanessa_figueiredo@hotmail.com; vanessa.figueiredo@ufms.br
} 
Resumen El artículo relata la investigación de las vivencias de placer y sufrimiento mental en un equipo de profesionales de la salud que atiende a personas con trastornos mentales en un Centro de Atención Psicosocial (CAPS), localizado en el interior de Mato Grosso do Sul, durante el 2012. A partir del enfoque psicodinámico del trabajo fueron analizadas las condiciones y la organización de trabajo prescrito y real, la movilización creativa y la existencia de sufrimiento y patologías. Once trabajadores participaron de cinco entrevistas colectivas que abordaron exigencias técnicas, relaciones socio-laborales, riesgos, tareas, normas, gestión, división del trabajo, responsabilidades, aplicación de inteligencia práctica y cooperación, existencia y reconocimiento de sufrimiento creativo. La presencia del sufrimiento patogénico y daños físicos o psicosociales fueron evaluados por la Escala de Placer-Sufrimiento en el Trabajo (ESPST) y por la Escala de Síntomas Relacionados al Trabajo (ESRT), que integran el inventario de Trabajo y Riesgos de Enfermedad (ITRA). Se verificó que las principales vivencias de placer están relacionadas con el modo como el equipo se relaciona, con el reconocimiento por parte de los usuarios y de los familiares, y con la autonomía para planear sus actividades. La falta de reconocimiento por parte de la gestión, la falta de seguridad en los atendimientos y la sobrecarga de trabajo fueron aspectos generadores de sufrimiento. Los resultados de la EPST en los ítems de Realización profesional $(3,6)$ y Libertad de expresión $(4,2)$ indican que las estrategias de mediación del sufrimiento se equilibran en el equipo por medio de la dinámica del reconocimiento. La ESRT señala que hay un riesgo moderado de síntomas y enfermedades físicas relacionadas a la sobrecarga de trabajo.

Palabras-clave:

sufrimiento; salud mental; psicodinámica. 
$\mathrm{E}$ sta pesquisa teve como objetivo abordar as vivências de prazer e de sofrimento envolvidas no trabalho de profissionais de saúde de um Centro de Atenção Psicossocial (CAPS) localizado no interior do Mato Grosso do Sul. Os CAPS's podem ser definidos como dispositivos estratégicos para a organização da rede de atenção à saúde mental e para a consolidação da reforma psiquiátrica brasileira (Campos et al., 2009). Constituem-se em serviços abertos eficientes para a diminuição de internações de pessoas que sofrem com transtornos mentais, psicoses, neuroses graves e demais quadros cuja severidade e/ou persistência demandam de cuidado intensivo e personalizado (Brasil, 2004a; Kantorski et al., 2010).

O CAPS proporciona atendimento diário à população de sua área de abrangência, oferecendo psicoterapia, tratamento medicamentoso, atendimento em grupo aos usuários e às famílias, oficinas terapêuticas, visitas domiciliares e atividades na comunidade. Os serviços buscam capacitar os usuários para que consigam se relacionar, circular e ocupar diversos espaços sociais de maneira independente (Brasil, 2004b; Paranhos-Passos \& Aires, 2013).

De acordo com Salles e Barros (2013), muitas vezes o indivíduo que sofre com transtorno mental severo também passa por perdas materiais e sociais, por conta de lhe serem negadas oportunidades e direitos, sendo essa a situação da maior parte da clientela que recorre ao CAPS. Segundo Santos (2009), diferentemente dos que têm condição financeira para buscar auxílio em consultórios particulares, esta população é composta por cidadãos que diariamente enfrentam violências que acometem sua condição humana, padecendo pela falta de emprego, moradia, família, vínculos afetivos, educação e sentidos para a vida, sentindo-se, muitas vezes, culpados pela sua própria doença e exclusão. Por sua vez, o profissional de saúde mental, ao adotar o paradigma psicossocial, reconhece o sofrimento ocasionado pela existência de "faltas" ancoradas na cultura.

Com essa compreensão sobre a segregação social, as práticas de cuidado e de reabilitação psicossocial devem desenvolver a autonomia, de forma a facilitar o acesso do usuário ao trabalho e ao lazer, fortalecer seus laços com a família e com a comunidade, para que, então, consiga exercer seus direitos e se reinserir socialmente (Brasil, 2004a). Segundo Nicácio e Campos (2004), o enfoque psicossocial de atendimento à saúde mental deve buscar reconstruir as relações entre a sociedade e as pessoas que sofrem com transtornos mentais, superando um modelo voltado apenas para a cura ao incluir formas de atenção que permitam a inserção social de um indivíduo entendido como portador de direitos.

Para isso, os profissionais de saúde devem estar engajados com as bases comunitárias de solidariedade, o que exige implicação política com o projeto antimanicomial no que se refere ao modo de se relacionar e entender o estigma que cerca a pessoa com adoecimento mental, revelando o compromisso ético e técnico dos profissionais com o campo da saúde mental e com a comunidade que solicita os serviços (Bezerra, 2007; Ramminger, 2006). Ainda, por ter como objetivo final a reinserção social do usuário, a reestruturação dos serviços de saúde mental pressupõe a aquisição de novos paradigmas e conceitos, e também uma nova identidade profissional, que se manifesta em um jeito renovado de trabalhar frente à reorganização dos serviços e às transformações nos processos de trabalho (M. B. B Silva, 2007; Lunardi, Lunardi, Silveira, Soares, \& Lipinski, 2004).

A concepção da clínica ampliada pautada na humanização requer o envolvimento mais intenso com os problemas dos usuários, que vai além do conhecimento técnico-científico, sendo necessário o estabelecimento de relações afetivas e a mobilização subjetiva dos profissionais da área para o desenvolvimento de suas atividades (Guimarães, Jorge, \& Assis, 2011; M. B. B. Silva, 2005; Ramminger \& Brito, 2012). Para Lancman e Pereira (2008), o cuidado de pessoas portadoras de transtornos mentais ocorre entre um indivíduo que sofre psiquicamente e outra que é responsável por melhorar seu quadro. Tal situação demanda grande envolvimento com o serviço prestado e o manejo prolongado com as pessoas atendidas, gerando preocupação, inquietação e sofrimento psíquico nos trabalhadores (E. A. Silva \& Costa, 2010).

Além das características relacionadas às próprias atividades desenvolvidas, Ferrer (2007), Karam (2008), M. B. B. Silva (2007) e Santos (2009) e verificaram a relação entre o sofrimento psíquico e as condições de trabalho nos CAPS, como a falta de equipamentos e a baixa remuneração. Lancman e Pereira (2008) também afirmam que os serviços não têm funcionado com uma infraestrutura mínima de operacionalidade, sendo comum encontrar uma quantidade insuficiente de funcionários, instalações inapropriadas, altas demandas para atendimento e avaliações de produtividade incoerentes com o objetivo final do serviço. Frente a essas condições e situações de trabalho, E. A. Silva e Costa (2010) identificaram sentimentos de desânimo, cansaço, ansiedade, frustração, tensão emocional, sobrecarga e estresse no trabalho. 
Assim, considerando a importância de uma verdadeira política de promoção da saúde mental voltada para os profissionais que atuam nos CAPS, visto sua importância para a consolidação do serviço, esta pesquisa buscou analisar as vivências de prazer e de sofrimento do contexto de trabalho e, ao mesmo tempo, atuar nos riscos frente ao sofrimento patogênico. Para isso, utilizou-se como referencial teórico a psicodinâmica do trabalho.

\section{Alguns conceitos básicos da psicodinâmica do trabalho}

A procura do prazer e a fuga do desprazer constituem uma aspiração constante para o trabalhador, em virtude das requisições instituídas no processo, nas relações e na organização do trabalho. Para Dejours (2007), o trabalho é sempre permeado pelo sofrimento, mas nem sempre o conflito entre a subjetividade e a organização do trabalho decorre em uma consequência lastimável.

Segundo Dejours e Aboudcheli (2007), a organização do trabalho define a prescrição das tarefas a serem realizadas em todo seu modo operatório e estabelece a divisão das pessoas no sistema hierárquico, dividindo suas responsabilidades e comando. Entretanto, como a prescrição nunca é suficiente para apreender o inesperado do cotidiano, o trabalho é compreendido pela psicodinâmica de como a atividade é realizada para dar conta da experiência real, a qual envolve gestos, posturas, saber-fazer, engajamento do corpo e da afetividade, inteligência, interpretação das situações, criatividade. Trabalhar não significa apenas produzir, mas também modificar a si mesmo, sendo que o prazer e o sofrimento estão em uma relação subjetiva da pessoa com seu trabalho, e a forma como de lidar com o impasse psíquico suscitado do confronto entre o prescrito e o real definirá se o sofrimento terá como destino a criatividade ou o adoecimento (Dejours, 2007).

O sofrimento criativo acontece quando o trabalhador consegue tolerar o sofrimento e superar os obstáculos e os fracassos impostos pela realidade laboral. Nesse processo, ao mesmo tempo em que se transforma pelo desenvolvimento de sua inteligência e capacidade, também torna possível transformar o sofrimento em prazer, ao fazer uso de sua inteligência prática. Para isso, é preciso que a organização do trabalho dê liberdade e reconheça o exercício da criatividade frente aos imprevistos.

O reconhecimento é compreendido como a retribuição simbólica pela constatação da contribuição individual empreendida para fazer funcionar o processo de trabalho frente às imperfeições da prescrição. $O$ julgamento da utilidade técnica e social do trabalho realizado, feito pela hierarquia, e do julgamento da particularidade e beleza do saber-fazer, realizado pelos colegas, valida o uso da engenhosidade e da inteligência nas situações de trabalho, e gera o sentimento de pertencer a um coletivo, edificando a identidade (Dejours, 2009).

A mobilização subjetiva permite a ressignificação do trabalho e o enfrentamento das situações de sofrimento por meio do reconhecimento do uso da inteligência prática e da cooperação, em um espaço público coletivo de discussão onde exista confiança e solidariedade. Entretanto, quando a instituição não possibilita a modificação das tarefas para resoluções de problemas, o indivíduo acaba utilizando estratégias defensivas para suportar a atividade, gerando tensão, desprazer e patologias relacionadas ao trabalho (Dejours, 2007, 2011). Ferreira e Mendes (2003) também apontam que, em um contexto laboral onde predominam vivências de sofrimento, há o aumento do custo humano devido ao esforço do trabalhador em se adaptar e compensar o trabalho.

Levando em conta a dinâmica das relações entre subjetividade e trabalho, esta pesquisa buscou levantar e analisar elementos do contexto laboral do CAPS decorrentes de vivências de prazer e sofrimento: condições e organização do trabalho prescrito e real (exigências técnicas, relações com colegas, chefia e usuários, riscos, responsabilidades, tipos de tarefas, normas, gestão, divisão do trabalho), existência e maneira como ocorre a mobilização criativa (inteligência prática, cooperação, sofrimento criativo, reconhecimento) e presença de sofrimento patogênico e patologias (existência de danos físicos e psicossociais, custo humano e sobrecarga).

\section{MÉTODO}

Ao adotar o referencial teórico-metodológico da psicodinâmica do trabalho, considerou-se o trabalho como eixo central de estruturação do indivíduo e priorizou-se o levantamento das fontes de prazer e de sofrimento na organização do trabalho. Além disso, procurou-se possibilitar um espaço de reflexão e de discussão sobre o significado do trabalho, de forma que os participantes percebessem os efeitos do trabalho sobre sua saúde em uma etapa pré-patológica (Merlo, Zanini, Furstenau, \& Pacini, 2004).

Pelo fato de ser uma proposta emancipatória, tornou-se necessário o engajamento da pesquisadora no estudo como coagente na transformação dos processos organizacionais e micro-organizacionais, de modo que 
a pesquisa não fosse apenas uma coleta de dados. Para isso, a prática adotada para a realização deste estudo foi a pesquisa-ação, a qual permite que o psicólogo desenvolva seu papel de clínico social - interessado na transformação do trabalho para a diminuição de fatores que geram sofrimento nos trabalhadores e redução do sofrimento -, como de conscientização e empoderamento dos participantes nas situações de trabalho, vinculando situações reais e vivências dos indivíduos (Bendassolli \& Soboll, 2011). Para a realização da pesquisa foi elaborada uma análise sociopsíquica do trabalho, partindo da organização do trabalho para compreender as vivências subjetivas como o prazer, o sofrimento, o processo saúde-adoecimento, bem como os mecanismos de defesa e de mediação do sofrimento que ocorrem no contexto do CAPS (Mendes, 2007).

\section{Local e participantes}

A pesquisa ocorreu em um CAPS II localizado no interior do Mato Grosso do Sul, e onze, dos treze funcionários, aceitaram participar: dois psicólogos, dois auxiliares de enfermagem, uma terapeuta ocupacional, a coordenadora da unidade, uma artesã, uma assistente social, um cuidador, um administrador e uma recepcionista. Destes, oito eram mulheres e três homens, com idades entre 23 e 60 anos, escolaridade variando do ensino fundamental ao superior, sendo seis funcionários casados, quatro solteiros e um divorciado. O tempo médio de trabalho variou entre sete anos, para a recepcionista e para os técnicos de enfermagem, até três meses para os mais recentes da equipe. A maioria dos funcionários ingressou no serviço público por meio de concurso (nove), e dois foram contratados, sendo a renda média dos profissionais de $\mathrm{R} \$ 1.736,36$.

\section{Procedimento}

Para dar início à pesquisa, foi apresentada a proposta de estudo aos funcionários em uma reunião, momento em que tiveram ciência da justificativa, objeto de estudo, objetivos e método adotado. Após, foi solicitada a participação voluntária dos funcionários, organizou-se o calendário das sessões, e foi-lhes apresentado o Termo de Consentimento Livre e Esclarecido (TCLE). A pesquisa teve aprovação do comitê de ética em 01/06/2012, sob n 01701212.7.0000.0021.

Os encontros foram realizados em salas do CAPS utilizadas para reuniões de equipe e de estudos de casos, e toda a pesquisa foi realizada entre os meses de maio e outubro de 2012. As escalas de Prazer-Sofrimento no Trabalho (EPST) e a de Sintomas Relacionados ao Trabalho (ESRT) foram aplicadas ao final dos cinco encontros em 10 funcionários, em um tempo médio de 15 minutos.

Foram realizadas cinco entrevistas coletivas, e houve oscilação no número de participantes a cada sessão, variando de quatro a 11 pessoas. Estas entrevistas buscaram levantar as vivências de prazer e de sofrimento em várias situações de trabalho, procurando contemplar os três eixos propostos por Mendes e Araújo (2012): organização do trabalho prescrito e real; mobilização subjetiva; e sofrimento, defesas e patologias.

\section{Instrumentos}

Foi aplicado um questionário sociodemográfico com perguntas abertas, cinco sessões de entrevista coletiva e duas escalas pertencentes ao Inventário do Trabalho e Riscos de Adoecimento (ITRA), validado por Mendes, Ferreira, Facas e Vieiras (2005).

A Escala de Prazer-Sofrimento no Trabalho (EPST), validada por Mendes et al. (2005), é composta por 24 itens que medem dois fatores para o prazer: realização profissional (vivência de gratificação profissional, orgulho e identificação com o trabalho realizado) e liberdade de expressão (vivência de liberdade para pensar, organizar e falar sobre seu trabalho); e dois fatores para o sofrimento, sendo esgotamento profissional (vivência de frustração, insegurança, desqualificação diante das expectativas de desempenho, gerando estresse, desgaste e esgotamento) e falta de reconhecimento (vivência de injustiça, indignação e desvalorização).

A Escala de Sintomas Relacionados ao Trabalho (ESRT), validada por Mendes et al. (2005), contém 32 itens distribuídos em três sintomas ocasionados a partir do enfrentamento do indivíduo com determinados contextos de trabalho: psicológicos (percepção negativa de si mesmo, da vida em geral e alterações de humor), sociais (isolamento social e dificuldades nas relações familiares e sociais) e físicos (dores no corpo e distúrbios 
fisiológicos). Os resultados são avaliados da seguinte maneira: para média de 1 a 2,3 os resultados para a EPST e ESRT são considerados satisfatórios; quando a média fica entre 2,3 a 3,7 considera-se o resultado moderado para a EPST, apontando a utilização de defesas e estado de alerta para os sintomas que a ESRT investiga. Quando as médias encontram-se acima de 3,7 são interpretadas do seguinte modo: EPST como apontando uso de estratégias de defesa e ESRT apontando estado crítico para os sintomas relacionados ao trabalho (Ferreira \&Mendes, 2003).

A Entrevista Coletiva Semiestruturada procurou permitir o desenvolvimento de um ambiente público de discussão sobre o trabalho e suas relações com os processos de subjetivação e a saúde do trabalhador (Mendes, 2007). Os temas tratados durante as entrevistas buscaram apreender as condições e a organização do trabalho, a mobilização criativa e o sofrimento, sendo abordados da seguinte maneira:

- $1^{\text {a }}$ Entrevista coletiva: tratou sobre o fazer dos profissionais a partir das seguintes questões-guia: $\mathrm{O}$ que você faz? Faça comentários sobre o seu fazer. Participaram 11 funcionários, que relataram sobre a convivência interdisciplinar e a necessidade de confiança entre os membros da equipe. Eles ressaltaram a necessidade e a importância da participação dos pacientes na arrecadação de fundos para a compra de material para as oficinas terapêuticas. Comentaram sobre as atividades e atribuições que não estariam dentro do prescrito para a equipe multiprofissional, a carência de cooperação dos outros serviços e a ausência de referência teórica e técnica em saúde mental. Expuseram a insatisfação de fazer menos do que poderiam devido à falta de recursos materiais e à perda de sentido do trabalho, à sobrecarga, à necessidade de conjugar a capacidade com a organização prescrita e ao espaço para programarem e colocarem em prática suas atividades. Apontaram também a paixão pela proposta do serviço e o reconhecimento/consideração dos pacientes e de colegas de fora do CAPS.

- 2a Entrevista coletiva: foram abordadas as condições de trabalho, e se utilizou as seguintes questões-guia: Falem sobre suas condições de trabalho; Falem sobre a segurança em relação aos casos de crise de pacientes dentro de um "serviço de portas abertas"; e Vocês se sentem seguros no trabalho, há condições que garantam essa segurança? Participaram 11 funcionários, que falaram sobre as dificuldades de colocar em prática o serviço de cuidado em saúde mental. Destacaram que têm uma coordenação flexível e reclamaram da falta de reconhecimento, das críticas e da interferência por parte do gestor regional de saúde. Colocaram, ainda, a existência de sobrecarga de trabalho e das estratégias de mediação. Apresentaram aspectos das condições de trabalho e as consequências da falta de equipamentos e recursos, além da falta de segurança no convívio com os pacientes em crise e as estratégias que os protegem nesses momentos.

- 3a Entrevista coletiva: abordou as relações socioprofissionais diante da resolução de problemas, através do uso das questões-guia: Falem sobre a divisão de tarefas; Como resolvem problemas por meio do coletivo? Nesta sessão, sete funcionários discorreram sobre a comunicação e o trabalho em equipe, a atuação no ambiente público e em ter que seguir os prescritos. Também contaram sobre o usuário como objeto intermediário e a carga afetiva do trabalho que realizam. Relataram questões como a divisão das tarefas, o cumprimento dos horários e o papel da coordenação do CAPS.

- 4a Entrevista coletiva: abordou o significado dos objetivos institucionais para esses profissionais, utilizando as seguintes questões-guia: $\mathrm{O}$ que os objetivos institucionais do CAPS significam para vocês? Como fazem para alcançá-los? Participaram cinco funcionários, que discorreram sobre a importância de conhecer o modo de trabalhar de cada um, da participação dos familiares dos pacientes nas reuniões do CAPS, das relações intersetoriais, das negociações com a rede pública e lembraram a amplitude da organização real do trabalho. Destacaram as vivências de prazer e as mudanças que o "trabalhar" gera no modo de ser do indivíduo.

- 5a Entrevista coletiva: buscou abordar quais tarefas os trabalhadores consideravam mais difíceis e aquelas que mais gostavam de executar, procurando discutir o sentido do trabalho para cada profissional por meio das seguintes questões-guia: Falem da execução de tarefas difíceis e como se desdobram; Falem da tarefa pela qual se realizam; Como é sua participação nessa atividade e que tempo e energia demandam? Participaram quatro funcionários, os quais destacaram o descaso com o serviço, o papel da política dentro da rede pública, a falta de profissionais, a sobrecarga e a união da equipe, bem como os arranjos coletivos para manter o serviço funcionando. 


\section{RESULTADOS E DISCUSSÃO}

\section{Organização do trabalho prescrito e real}

A organização do trabalho envolve os aspectos que abrangem as relações sociais estabelecidas no ambiente organizacional, as condições físicas e materiais, e a divisão de tarefas, visto que as vivências de prazer ou de sofrimento estão relacionadas à interação entre esses fatores.

Entre as diversas atividades que os profissionais exercem, algumas são mais prazerosas do que outras, como as realizadas fora da instituição, o futebol, as visitas domiciliares e as caminhadas. Elas são vivenciadas como fonte de prazer, pois permitem e demandam um espaço para os profissionais pensarem e programarem ações e, dessa forma, descentralizam o processo de decisão, dando autonomia ao profissional, o que estimula sua criatividade (R. R. Silva, 2004; Rossi, 2008). Os profissionais entrevistados no CAPS revelaram que têm liberdade para programar as atividades que são realizadas dentro e fora da instituição, já que a coordenação possibilita a descentralização do poder, o que é uma fonte de prazer para os profissionais da organização.

Outro ponto importante é a existência de uma relação de solidariedade e companheirismo, pois, apesar de cada profissional ter sua tarefa delimitada, no caso de alguém não estar presente ou estar impossibilitado de fazê-la, os colegas ajudam e realizam o trabalho, como é o caso do acolhimento inicial, que pode ser feito por todos:

Nós somos uma equipe bem preparada, caso um de nós não possa fazer sua tarefa, outro pode e faz do mesmo jeito. Inclusive o acolhimento é feito por todos, quem estiver livre no momento da chegada do novo paciente faz. (Entrevistado 3, entrevista coletiva, 14/05/2012).

Segundo Dejours, Abdoucheli e Jayet (2007) é possível alcançar o prazer e a realização por meio da solidariedade e da identificação incentivadas pela equipe. $\mathrm{O}$ trabalho em equipe é um dos aspectos da dinâmica do reconhecimento, contribuindo para idealizar, construir, desejar e confirmar a identidade almejada por meio do trabalho na saúde mental. Assim, as relações sociais estabelecidas no CAPS são essenciais para os profissionais continuarem trabalhando na instituição, evidenciando o quanto o funcionamento psíquico está associado à organização do trabalho e ao peso da confiança e da cooperação, que contribuem para os sentimentos de apoio e alívio frente aos problemas que surgem no trabalho (E. A. Silva, 2007).

Como pontua Santos (2009), o profissional da saúde mental é o principal ator de mudanças e transformações das políticas públicas de saúde, sendo esse compromisso efetivado na equipe estudada pela disposição com relação ao cuidado e à reinserção psicossocial dos usuários, e pela responsabilidade pelo tratamento ao ver o sofrimento de uma população que vive muitas vezes às margens da sociedade. Entretanto, a vontade individual nem sempre basta, pois, conforme um dos participantes, "tem tanta coisa que a gente gostaria de fazer pelos nossos pacientes, mas infelizmente não conseguimos pôr em prática tudo que planejamos, e muitas vezes nossas mãos são atadas pela politica". (Entrevistado 2, entrevista coletiva, 21/05/2012).

Uma das causas do sofrimento é que alguns profissionais, antes de entrarem no CAPS, já idealizam a realização de projetos e atividades com as famílias ou com patologias específicas dos usuários, o que nem sempre é possível, em especial devido à falta de profissionais. Além disso, a organização do trabalho gera medo e sentimentos de ameaça à integridade física e psíquica dos profissionais, sendo que o funcionamento psíquico da equipe é confrontado quando existe a ameaça ao próprio cuidador.

Os entrevistados relataram que sentem insegurança e medo de acidentes e de serem agredidos pelos usuários quando estão em surto, pois o guarda contratado cuida apenas do patrimônio:

[...] ficamos muito apreensivos quando algum paciente está em surto. Corremos perigos reais aqui, mas parece que os governantes não ligam pra isso, porque o guarda aqui é só para o patrimônio como se isso fosse mais importante que nossa integridade física. (Entrevistado 1, entrevista coletiva, 17/06/2012).

A precarização da organização apontada pelos profissionais desgasta as condições de engajamento do indivíduo, pois gera um conflito entre a subjetividade do trabalhador e sua realidade laboral, colaborando para o acúmulo de energia psíquica (R. R. Silva, 2004). 
Observou-se também que o funcionamento da instituição não está de acordo com o prescrito, pois não conta com área externa adequada para o desenvolvimento de atividades ou esporte, nem espaço apropriado para refeições ou descanso, não conseguindo contemplar os objetivos do CAPS de proporcionar atendimento clínico e reabilitação social dos usuários pelo acesso ao trabalho, lazer, exercício dos direitos civis e fortalecimento dos laços familiares e comunitários (Brasil, 2004a).

Muitas propostas prescritas no Manual do CAPS (Rabelo, Mattos, Coutinho, \& Pereira, 2007) não são colocadas em prática pela falta de condições de trabalho e material para a realização das atividades e oficinas, resultando na vivência de sofrimento e desgaste dos profissionais ao sentirem que fazem menos do que poderiam e deveriam, e fazendo apenas o que dá na situação real.

Para colocar atividades e oficinas em prática, os funcionários e os usuários se mobilizam em prol de arrecadar ou levar recursos e materiais básicos para o CAPS, já que muitos consideram a instituição sua segunda casa. Muitas vezes, os próprios usuários, aqueles que deveriam usufruir do serviço público de saúde mental como direito, são os que repõem materiais para os profissionais, como foi exemplificado por um participante ao descrever a situação do dia anterior, em que "[...] um paciente apareceu com um pacote de café e açúcar e disse aqui ó que minha mãe tirou na venda pro CAPS... meus olhos encheram de água, agradeci e fui chorar na outra sala". (Entrevistado 4, entrevista coletiva, 28/06/2012).

A falta de condições de trabalho prejudica a qualidade das atividades dos profissionais, a qualidade do serviço de saúde e até mesmo a saúde dos usuários. Os materiais, quando solicitados, demoram a chegar, gerando descontentamento pela impossibilidade de escolher as atividades a serem efetuadas pela falta de recursos existentes. Como disse um dos entrevistados, "gostaria de fazer tanta coisa, tinha vontade de colocar tantas atividades em prática, mas infelizmente, como você pode ver, não tem como". (Entrevistado 10, entrevista coletiva, 05/08/2012).

Quando o profissional se revela impossibilitado de trabalhar, emergem dilemas sobre sua formação e as funções que desempenha. Os trabalhadores têm dificuldade em atingir todas as propostas preconizadas, como as oficinas e as atividades básicas de reuniões com os familiares, pois faltam mesas, cadeiras, salas, telefone, internet, computador, impressora, remédios e receituários. Isso demanda o uso da inteligência prática e da criatividade para que os profissionais consigam desenvolver seu trabalho com as condições mínimas necessárias. Ademais, a falta do apoio da gestão mostra-se prejudicial também ao andamento da instituição. A falta de reconhecimento dificulta o estabelecimento de um modo de agir coletivo, ou seja, uma única maneira dos profissionais conferirem significados, sentidos e regras comuns às situações inesperadas no trabalho (Morrone, 2001), o que é retratado pela fala do entrevistado que declara ser "difícil trabalhar em um lugar onde sempre temos situaçôes novas, e nem sempre sabemos como agir”. (Entrevistado 6, entrevista coletiva, 08/08/2012).

A organização real do trabalho no CAPS ocorre na relação entre profissional e usuário, na forma em que o primeiro apresenta o significado do trabalho ao interagir e manter o vínculo com as pessoas atendidas, o que depende do diálogo, da paciência, do equilíbrio psíquico do profissional e de como ele consegue agir perante as situações de confronto no dia a dia (Dejours, 2004). Essa organização do trabalho, ao permitir o desenvolvimento da mobilização da inteligência prática, do espaço público da fala e da cooperação, acaba tornando possível, mesmo de maneira indireta, a vivência de prazer (Dejours \& Gernet, 2011).

Mas também pode ocorrer, como afirma Migott (2001), um conflito gerado pela lacuna entre o desejo do profissional e a realidade do trabalho, que acontece quando a relação entre o trabalhador e a organização não são compatíveis, como é o caso da instituição estudada. Nesses momentos pode aparecer o bloqueio, o cansaço, a frustração, as dificuldades das relações interpessoais, a desesperança; enfim, sentimentos que levam ao sofrimento e à tensão pessoal e profissional.

\section{Sobre o atendimento}

Uma questão relacionada às atividades dos profissionais é a dificuldade em ver o sofrimento do outro. Segundo Dejours (2003), o sofrimento do outro não é entendido apenas de forma racional, pois, quando o profissional percebe o sofrimento do usuário, inicia um processo afetivo, que se movimenta perante a sua própria experiência de sofrimento. Ao identificar o sofrimento do outro, o profissional também se depara com situações que lhe exigem diversas habilidades, tanto aquelas praticadas cotidianamente quanto as que ainda são desconhecidas - que serão arquitetadas no desenrolar do tratamento. Todas essas aptidões e invenções farão parte, portanto, das capacidades desse trabalhador, que deve perceber a atenção e o cuidado a serem dispensados 
ao usuário em cada momento e, em especial, em situação de crise, como relatado por um participante, ao dizer que "toda a equipe sente quando algum paciente entra em surto, da recepcionista aos técnicos, uns mais, outros menos, mas ninguém sai imune quando algum paciente entra em crise". (Entrevistado 7, entrevista coletiva, 12/08/2012).

É por meio da prática cotidiana com cada caso que os profissionais aprendem sobre o sofrimento do outro e como promover a mudança da condição de vida do usuário. A concretização do novo modelo de atenção em saúde mental vem da aquisição de aptidões, como a habilidade de escutar, de estabelecer vínculos e diagnosticar, de sentir o humor do outro, de viver uma intersubjetividade e cooperar com os colegas de trabalho (Santos, 2009).

No CAPS estudado essas atividades, tão complexas e desgastantes, são realizadas por um pequeno número de profissionais, que têm de suprir as demandas do serviço de saúde mental, as quais crescem a cada dia, o que gera sofrimento pelo grande esforço para atender todas as solicitações. Isso pode ser observado pela fala seguinte, em que o entrevistado 9 reporta que "é muito ruim trabalhar com a equipe desfalcada, não estamos dando conta e estamos liberando os pacientes mais cedo. Quase todo dia chega um paciente novo, estamos sempre nos virando pra atender a todos, desse jeito ficamos sobrecarregados e cansados". (Entrevistado 9, entrevista coletiva, 08/08/2012).

De acordo com Dejours (2003), trabalhar é conviver com a experiência da pressão, compartilhando um espaço em comum, encarar a resistência do real e estabelecer sentidos no coletivo. No CAPS o trabalho nunca é individual e o profissional necessita do olhar do colega para ser reconhecido, instituindo um espaço social por onde passa a atualização de seus vínculos afetivos. Dessa forma, o trabalho em equipe ocasiona expectativas de todos em relação a todos, e o amadurecimento e a honestidade são modos de lidar com essas expectativas porque traz condições mais favoráveis ao convívio no trabalho, que permite momentos de descontração e de estabelecimento de vínculos entre os colegas. Conforme o entrevistado 8, o melhor do trabalho é o relacionamento sociolaboral, "[...] é quando a gente se reúne, ri, brinca e fofoca também (risos)". (Entrevistado 8, entrevista coletiva, 16/08/2012).

A mobilização subjetiva está presente no modo de agir comunicacional e é necessária no contexto do CAPS, onde não existe rotina e há demanda pela flexibilidade dos papéis, já que o profissional é orientado no cotidiano pelo imprevisto, e seu produto é a estabilidade emocional da pessoa com sofrimento psíquico (Ferrer, 2007).

\section{Custo psíquico no atendimento a pessoas com transtornos mentais}

Os resultados das escalas de Prazer-Sofrimento no Trabalho (EPST) e de Sintomas Relacionados ao Trabalho (ESRT) estão inter-relacionados e indicam que os profissionais do CAPS apresentam vivências moderadas de prazer-sofrimento no trabalho, com predomínio das vivências de prazer, utilizando estratégias de mediação defensivas. As médias dos fatores de vivências de sofrimento obtiveram pontuação próxima dos fatores relativos às vivências de prazer, e podem ser visualizadas nas Tabelas 1 e 2 .

TABELA 1. Média e desvio padrão da escala de Prazer-Sofrimento no Trabalho (EPST) aplicada em trabalhadores do CAPS do interior do Mato Grosso do Sul, em 2012.

\begin{tabular}{lll}
\hline \multicolumn{1}{c}{ Fatores } & $M$ & $D P$ \\
Esgotamento emocional & 2,5 & 1,2 \\
Realização profissional & 3,6 & 0,87 \\
Liberdade de expressão & 4,2 & 0,53 \\
Falta de reconhecimento & 2,0 & 2,53 \\
\hline
\end{tabular}

TABELA 2. Média e desvio padrão da escala de Sintomas Relacionados ao Trabalho (ESRT), aplicada em trabaIhadores do CAPS do interior do Mato Grosso do Sul, em 2012.

\begin{tabular}{lcc}
\multicolumn{1}{c}{ Fatores } & $M$ & $D P$ \\
Sintomas físicos & 1,71 & 1,6 \\
Sintomas psicológicos & 1,28 & 0,16 \\
Sintomas sociais & 1,22 & 0,32 \\
\hline
\end{tabular}


A realização profissional está relacionada ao fato dos profissionais encontrarem prazer ao serem reconhecidos por sua dedicação em relação aos usuários e seus familiares, aumentando, com isso, a afetividade entre eles, como observado na fala do entrevistado 10, quando diz ser "maravilhoso quando os pacientes nos elogiam, ou quando os familiares chegam aqui e dizem que seus parentes estão bem graças a nós". (Entrevistado 10, entrevista coletiva, 10/09/2012).

Ainda relacionado ao item realização profissional, observa-se o alcance do prazer por meio da solidariedade e da identificação incentivadas pela equipe, e enfatiza a relação entre profissional e usuário como destaque da ação terapêutica, pois o cuidado desenvolvido no tratamento suscita julgamentos que contemplam a dinâmica do reconhecimento (Dejours, 2004). Os profissionais relatam que alcançam na relação usuário-profissional o sentido para o seu trabalho, por meio do registro no campo social, demonstrando o valor de seus vínculos e o peso da avaliação dos usuários para seu bem-estar:

[...] o que me dá mais prazer é ver os paciente progredindo é melhorando cada dia mais; acho que isso é o mais gratificante do nosso trabalho, faz um bem enorme pra equipe ver um paciente que chegou aqui sem perspectiva e agora até está no mercado de trabalho. (Entrevistado 11, entrevista coletiva, 03/10/2012).

Mesmo com todas as restrições que a falta de condições de trabalho impõe, ainda assim a liberdade de expressão no trabalho foi um importante item gerador de prazer, proporcionado, inclusive, pela coordenação, que possibilita espaços de escuta, aceitando questionamentos e sugestões dos funcionários.

Com relação aos fatores de vivência de sofrimento, a falta de reconhecimento por parte dos gestores externos da instituição apareceu nos relatos, ao exigirem o cumprimento de metas consideradas quase impossíveis e nunca suficientes, mesmo não fornecendo as condições de trabalho mínimas necessárias. Os funcionários queixaram-se do controle, das críticas e das ordens que recebem da direção regional de saúde da qual fazem parte, que interroga e julga a qualidade e a utilidade do trabalho desenvolvido. Os profissionais, ao falarem sobre a falta de reconhecimento vivenciada, problematizaram a validade de um julgamento desqualificado, que negligencia o engajamento do indivíduo, baseado em parâmetros alheios ao trabalho vivo, e sentem a falta do reconhecimento conquistado pelo seu trabalho. De acordo com um dos participantes, quando a direção regional vai até a instituição, "eles vêm aqui, nos dão ordens, dizem que está tudo errado e vão embora; não querem nem saber como realmente o serviço está sendo realizado, nem sobre como estamos nos virando pra fazer dar certo". (Entrevistado 12, entrevista coletiva, 27/09/2012).

Ao debaterem a política existente na saúde mental, os entrevistados colocaram em xeque o julgamento do valor social do seu trabalho e de seus esforços por pessoas que não conhecem as atividades que devem ser desenvolvidas na instituição nem os preceitos da reforma psiquiátrica e, por isso, fazem exigências eticamente discutíveis. Esta tensão entre os desejos da organização e os valores éticos do profissional é fonte de sofrimento, apresentando-se como uma consequência afetiva de uma contradição moral-prática (R. R. Silva, 2004).

As avaliações injustas e o pouco reconhecimento conferido desvalorizam o trabalho realizado fazem com que os profissionais se submetam às metas traçadas pela gestão, intensificando seus esforços para fazer cada vez mais e melhor suas atividades, via ideologia da excelência (Franco, Druck, \& Seligmann-Silva, 2010). Por sua vez, a impressão dos trabalhadores de que não darão conta das responsabilidades por excesso de atribuições e sobrecarga de trabalho foi constatada nas entrevistas e relacionada a resultado da ESRT, indicando um risco moderado da equipe desenvolver sintomas e doenças físicas.

Em contrapartida, para que o trabalho atue como fonte de saúde é preciso que o trabalhador seja reconhecido, posto o reconhecimento habita a possibilidade de dar sentido e transformar o sofrimento vivenciado. Para Merlo et al. (2003), o reconhecimento é requisito indispensável no processo de mobilização subjetiva da inteligência e da personalidade no trabalho, desempenhando um papel essencial na possibilidade de modificar o sofrimento em prazer. No CAPS estudado verificou-se que mesmo sem o reconhecimento por parte da gestão externa, a coordenação interna possibilita a dinâmica pela constatação da contribuição dada pelos trabalhadores para o processo de trabalho e, com isso, a mobilização criativa, possibilitando a transformação do sofrimento em prazer.

O trabalho com pessoas em situação de miséria e o sentimento de inutilidade em efetivar melhorias objetivas e concretas foram citadas como causas de esgotamento emocional (EPST), pelo fato de a atividade se caracterizar essencialmente pela construção das relações afetivas. 


\section{CONSIDERAÇÕES FINAIS}

A partir da compreensão das vivências no contexto de trabalho, verificou-se, entre as principais causas de sofrimento dos trabalhadores do CAPS, a falta de reconhecimento por parte dos gestores, a sobrecarga de trabalho e a falta de segurança dentro da instituição. Entre as principais causas de prazer foram citados o relacionamento da equipe, a autonomia para planejar as atividades, bem como a possibilidade de colocá-las em prática, e o reconhecimento advindo dos usuários e seus familiares.

A adoção da psicodinâmica permitiu revelar, a partir do discurso dos trabalhadores, a forma pela qual a equipe do CAPS preserva o equilíbrio psíquico perante as pressões do trabalho, sendo que a construção dos coletivos se mostrou essencial para o trabalho interdisciplinar em saúde mental e também para a estabilização da equipe. Observou-se que as vivências de prazer-sofrimento equilibram-se, cujas estratégias de mediação do sofrimento não estão esgotadas, pois existem atitudes cooperativas e dinâmicas de reconhecimento que beneficiam a modificação do sofrimento em prazer e estão na base da construção da identidade profissional e do vínculo que os profissionais estabelecem com seu trabalho. Por isso, é indispensável que os mecanismos de reconhecimento do trabalhador da área de saúde mental sejam intensificados por meio de uma gestão de pessoas que proporcione melhores condições de trabalho e permita a visibilidade de suas ações no campo social.

Levando em conta que o cuidado de pessoas com sofrimento mental depende fundamentalmente do engajamento dos profissionais com o usuário, com a equipe e com a população, sendo essa a participação que estabelece e ampara a rede pública de serviços em saúde mental, é necessário que sejam realizadas mais pesquisas e intervenções sobre as vivências de sofrimento e prazer no contexto laboral do CAPS. Na instituição pesquisada, sugere-se o uso da clínica psicodinâmica do trabalho como forma de promoção de saúde mental, a qual possibilita o engajamento e a expansão da subjetividade dos trabalhadores na busca da transformação das estratégias defensivas em mobilização criativa, e do sofrimento em prazer.

\section{REFERÊNCIAS}

Bendassolli, P. F., \& Soboll, L. A. P. (Orgs). (2011). Clínicas do trabalho: novas perspectivas para a compreensão do trabalho na atualidade. São Paulo: Atlas.

Bezerra, B., Jr. (2007). Desafios da reforma psiquiátrica no Brasil. Physis: Revista de Saúde Coletiva, 17(2), 243-250. doi:10.1590/S0103-73312007000200002

Brasil, Ministério da Saúde, Secretaria de Atenção à Saúde (2004a). Legislação em Saúde Mental: 1990-2004 (5a ed. amp.). Recuperado em 20 de maio, 2013, de http://portalsaude.saude.gov.br.

Brasil, Ministério da Saúde, Secretaria de Atenção à Saúde, Departamento de Ações Programáticas Estratégicas (2004b). Saúde Mental no SUS: Os Centros de Atenção Psicossocial. Recuperado em 16 de maio, 2013, de http://portalsaude.saude.gov.br.

Campos, R. T. O., Furtado, J. P., Passos, E. Ferrer, A. L., Miranda, L., \& Gama, C. A. P. (2009). Avaliação da rede de centros de atenção psicossocial: entre a saúde coletiva e a saúde mental. Rev. Saúde Pública, 43(supl. 1), 16-22. doi:10.1590/S003489102009000800004

Dejours, C. (2003). A banalização da injustiça social (5a ed.). Rio de Janeiro: Editora FGV.

Dejours, C. (2004). Subjetividade, trabalho e ação. Revista Produção, 14(3), 27-34.

Dejours, C. (2007). Psicodinâmica do trabalho na pós-modernidade. In A. M. Mendes, S. C. C. Lima, \& E. P. Facas (Orgs.), Diálogos em psicodinâmica do trabalho (13-26). Brasília: Editora Paralelo 15.

Dejours, C. (2009, Setembro). Entre o desespero e a esperança: como re-encantar o trabalho. Dossiê: Qual é o sentido do trabaIho? Revista CULT, (139), 49-53.

Dejours, C. (2011). Addendum. In S. Lancman \& L. Sznelwar (Org.), Christophe Dejours: da psicopatologia à Psicodinâmica do Trabalho. (3a ed. rev, pp.57-123). (F. Soudant, S. Lancman, \& L. I. Sznelwar, Trad.). Brasília: Paralelo.

Dejours, C., \& Abdoucheli, E. (2007). Itinerário teórico em psicopatologia do trabalho. In C. Dejours, E. Abdoucheli, \& C. Jayet (Orgs.), Psicodinâmica do trabalho: contribuições da Escola Dejouriana à análise da relação prazer, sofrimento e trabaIho (pp. 119-145). São Paulo: Atlas.

Dejours, C., Abdoucheli, E., \& Jayet, C. (2007). Psicodinâmica do trabalho. Contribuições da escola dejouriana a analise da relação prazer, sofrimento e trabalho. São Paulo: Atlas.

Dejours, C., \& Gernet, I. (2011). Trabalho, subjetividade e confiança. In L. I. Sznelwar (Org.), Saúde dos bancários (pp. 33-44). São Paulo: Editora Gráfica Atitude Ltda. 
Ferreira, M. C., \& Mendes, A. M. (2003). Trabalho e riscos de adoecimento:o caso dos auditores oficiais da Previdência Social Brasileira. Brasília: Ler, Pensar e Agir.

Ferrer, A. L. (2007). Sofrimento psíquico dos trabalhadores inseridos nos Centros de Atenção Psicossocial: entre o prazer e a dor de lidar com a loucura. Dissertação de mestrado, Universidade Estadual de Campinas, Campinas, SP, Brasil.

Franco, T., Druck, G., \& Seligmann-Silva, E. (2010). As novas relações de trabalho, o desgaste mental do trabalhador e os transtornos mentais no trabalho precarizado. Revista Brasileira de Saúde Ocupacional, 35(122), 229-248. doi:10.1590/S030376572010000200006

Guimarães, J. M. X., Jorge, M. S. B., \& Assis, M. M. A. (2011). (In)satisfação com o trabalho em saúde mental: um estudo nos Centros de Atenção Psicossocial. Revista Ciência e Saúde Coletiva, 16(4), 2145-2154.

Kantorski, L. P., Jardim, V. M. R., Coimbra, V. C. C., Hypólito, A. M., Guedes, A. C., Meirelles, M. C., ...Cortes, J. M. (2010). Avaliando a política de saúde mental num CAPS: a trajetória no movimento antimanicomial. Estudos e Pesquisas em Psicologia, 10(1), 242-263.

Karam, H. (2008). Centralidade do trabalho e saúde mental pública. In A. M. Mendes (Org.), Trabalho e Saúde - o sujeito entre emancipação e servidão (pp. 139-152). Curitiba: Juruá.

Lancman, S., \& Pereira, L. M. F. (2008). Introdução. In S. Lancman (Org.), Políticas públicas e processos de trabalho em saúde mental (pp. 9-28). Brasília: Paralelo 15

Lunardi, V. L., Lunardi, W. D., Filho, Silveira, R. S., Soares, N. V., \& Lipinski, J. M. (2004). O cuidado de si como condição para o cuidado dos outros na prática de saúde. Revista Latino-Americana de Enfermagem, 12(6), 933-939. doi:10.1590/S010411692004000600013

Mendes, A. M. (2007). Psicodinâmica do trabalho: teoria, método, pesquisas. São Paulo: Casa do Psicólogo.

Mendes, A. M., \& Araújo, L. K. R. (2012). Clínica psicodinâmica do trabalho: o sujeito em ação. Curitiba: Juruá.

Mendes, A. M., Ferreira, M. C., Facas, E. P., \& Vieira, A. P. (2005). Validação do Inventário de Trabalho e Riscos de Adoecimento - ITRA. Trabalho apresentado no IV Congresso de Psicologia Norte-Nordeste, Salvador, BA. 2005, Maio, 25 a 28.

Merlo, A. R. C., Vaz, M. A., Spode, C. B., Elbern, J. L. G., Karkow, A. R. M., \& Vieira, P. R. B. (2003). O trabalho entre prazer, sofrimento e adoecimento: a realidade dos portadores de lesões por esforços repetitivos. Psicologia \& Sociedade, 15(1), 117-136. doi:10.1590/S010271822003000100007

Merlo, A. R., C., Zanini, P. A., Furstenau, C. R., \& Pacini, L. (2004). As transformações no serviço público e a saúde dos trabalhadores da seguridade social de Porto Alegre. In A. R. C. Merlo (Org.), Saúde do trabalhador no Rio Grande do Sul: realidade, pesquisa e intervenção (pp. 361-378). Porto Alegre: Editora da UFRGS.

Migott, A. M. B. (2011). Cuidado construtivo: desvelando questões existenciais entre o agir ético e o técnico. Série Enfermagem (4). Passo Fundo, RS: UPF.

Morrone, C. F. (2001). "Só para não ficar desempregado" - Ressignificando o sofrimento psíquico no trabalho: estudo com trabalhadores em atividades informais. Dissertação de mestrado, Universidade de Brasília, Brasília, DF, Brasil.

Nicácio, F., \& Campos, G. W. de S. (2004). A complexidade da atenção às situações de crise - contribuições da desinstitucionalização para a invenção de práticas inovadoras em saúde mental. Revista de Terapia Ocupacional da Universidade de São Paulo, 15(2), 71-81. doi: 10.11606/issn.2238-6149.v15i2p71-81

Paranhos-Passos, F., \& Aires, S. (2013). Reinserção social de portadores de sofrimento psíquico: o olhar de usuários de um Centro de Atenção Psicossocial. Physis: Revista de Saúde Coletiva, 23(1), 13-31. doi:10.1590/S0103-73312013000100002

Rabelo, A. R., Mattos, A. A. Q., Coutinho, D. M., \& Pereira, N. N. (2007). Um manual para o CAPS: Centro de Atenção Psicossocial. Salvador: EDUFBA.

Ramminger, T. (2006). Trabalhadores de saúde mental: reforma psiquiátrica, saúde do trabalhador e modos de subjetivação nos serviços de saúde mental. Santa Cruz do Sul, RS: EDUNISC.

Ramminger, T., \& Brito, J. C. (2012). "Cada Caps é um Caps": uma coanálise dos recursos, meios e normas presentes nas atividades dos trabalhadores de saúde mental. Psicologia \& Sociedade, 24(1), 150-160. doi:10.1590/S010271822011000400018

Rossi, E. Z. (2008). Reabilitação e reinserção no trabalho de bancários portadores de LER/DORT: análise psicodinâmica. Tese de doutorado, Universidade de Brasília, Brasília, DF, Brasil.

Salles, M. M., \& Barros, S. (2013). Transformações na atenção em saúde mental e na vida cotidiana de usuários: do hospital psiquiátrico ao Centro de Atenção Psicossocial. Saúde em Debate, 37(97), 324-335. 
Santos, A. V., Jr. (2009). Organização do trabalho e prazer-sofrimento dos profissionais de um centro de atenção psicossocial. Dissertação de mestrado, Universidade de Brasília, Brasília, DF, Brasil.

Silva, E. A. (2007). Dores dos cuida-dores em saúde mental: estudo exploratório das relações de (des)cuidado dos profissionais de saúde mental em Centros de Atenção Psicossocial de Goiânia - GO. Dissertação de mestrado, Universidade de Brasília, Brasília, DF, Brasil.

Silva, E. A., \& Costa, I. I. (2010). O profissional de referência em saúde mental: das responsabilizações ao sofrimento psíquico. Revista Latinoamericana de Psicopatologia. Fundamental, 13(4), 635-647. doi:10.1590/S1415-47142010000400007

Silva, M. B. B. (2005). Atenção psicossocial e gestão de populações: sobre os discursos e as práticas em torno da responsabilidade no campo da saúde mental. Physis: Revista de Saúde Coletiva, 15(1), 127-150. doi:org/10.1590/S010373312005000100008

Silva, M. B. B. (2007). O técnico de referência no Centro de Atenção Psicossocial: uma nova especialidade no campo da saúde mental? Revista Vivências (32), 227-223.

Silva, R. R. (2004). Profissão pastor: prazer e sofrimento. Uma análise psicodinâmica do trabalho de líderes religiosos neopentecostais e tradicionais. Dissertação de mestrado, Universidade de Brasília, Brasília, DF, Brasil. 